\title{
Primer reporte de Demodex gatoi en Argentina
}

\author{
Céspedes, J. ${ }^{1}$; Borrás, P. ${ }^{2}$; P.Tort, G. ${ }^{3}$ \\ ${ }^{1}$ Director Clínica Veterinaria, Oroño 3062, Rosario, Santa Fe, Argentina. \\ ${ }^{2}$ Veterinaria Panda, Ruiz Huidobro 4771, Buenos Aires, Argentina. \\ ${ }^{3}$ Hospital Veterinario Virreyes, San Fernando, Buenos Aires. \\ E-mail: vetcespedes@gmail.com
}

\begin{abstract}
Resumen
Céspedes, J.; Borrás, P.; P.Tort, G.: Primer reporte de Demodex gatoi en Argentina. Rev. Vet. 31: 1, 92-94, 2020. En la presente comunicación breve se describe el primer caso de Demodex gatoi en Argentina, en un gato hembra castrada, de la raza Bengali, oriunda de Buenos Aires. El diagnóstico fue clínico y por observación de los ácaros. A su vez, se describe el tratamiento instaurado.
\end{abstract}

Palabras clave: gato, Demodex gatoi, síntomas, tratamiento.

\begin{abstract}
Céspedes, J.; Borrás, P.; P.Tort, G.: First report of Demodex gatoi in Argentina. Rev. Vet 31: 1, 92-94, 2020. In this communication we describe the first case of Demodex gatoi in Argentina in a neutered female Bengal cat, from Buenos Aires. Diagnosis was performed by clinical examination and the observation of mites. In addition, the administered treatment is presented.
\end{abstract}

Key words: cat, Demodex gatoi, symptoms, treatment.

\section{INTRODUCCIÓN}

La demodexia felina es una enfermedad dermatológica poco frecuente, producida por los ácaros Demodex cati, Demodex gatoi y especies innominadas ${ }^{4,6,9} . D$. gatoi fue descrito por primera vez en Estados Unidos, en $1981{ }^{3}$. Es un artrópodo que se caracteriza por su pequeñez: las hembras miden 100 micrómetros mientras que los machos asumen 90 micrómetros de longitud. Se localiza en el estrato córneo de la piel ${ }^{6}$.

A diferencia de $D$. cati, genera un cuadro pruriginoso y contagioso, generalmente en gatos inmunocompetentes ${ }^{1,7,9}$. Se ha descrito cierta predisposición en algunas razas como el Cornish rex, Burmese, Siamés y Persa ${ }^{7,9}$. Los principales signos clínicos se caracterizan por un prurito que puede ser moderado o intenso, zonas de alopecia, eritema y lesiones auto-inflingidas que se distribuyen en cara, cuello, codos y patas ${ }^{1,9}$.

Sin embargo, algunos gatos pueden albergar gran cantidad de ácaros sin manifestar signos clínicos, por lo cual actúan como portadores ${ }^{2}$. El diagnóstico se puede realizar obteniendo los artrópodos mediante raspajes cutáneos o cinta de acetato, para luego observarlos con microscopio mediante técnicas copro-parasitológicas de flotación ${ }^{2,7,9}$.

La identificación se basa en la morfología típica de este demodex y su localización superficial ${ }^{2}$. El tratamiento de la patología es un verdadero desafío, debido

Recibido: julio 2019 / Aceptado: octubre 2020 a que requieren largos períodos de medicación y no existen protocolos específicos ${ }^{9}$.

El objetivo de este trabajo fue presentar el primer reporte de D. gatoi en felinos domésticos de Argentina.

\section{MATERIAL Y MÉTODOS}

El reporte del caso clínico detalló que el felino era una hembra castrada, de 4 meses de edad, de raza bengali (Figura 1), remitida a la clínica veterinaria de uno de los autores de esta comunicación. La gata padecía diarreas y prurito intenso, que habían comenzado desde hacía 15 días. El animal era oriundo de un criadero de la ciudad de Buenos Aires.

Desde que llegó a su nuevo hogar nunca realizó deposiciones formadas. El prurito se manifestó con rascado de la piel, lamido excesivo y mordeduras en todo el cuerpo. Convivía con otro gato, macho castrado de un año y medio de edad, raza azul ruso, que al tiempo comenzó con los mismos signos clínicos de prurito y diarrea.

A la palpación, el examen clínico reveló inflamación de las asas intestinales, así como eritema en cabeza y cuello. La piel presentaba eritema únicamente en labios, sin lesiones por rascado ni zonas alopécicas causadas por prurito, el cual asumió intensidad moderada. Se solicitaron estudios de materia fecal y hematología.

Fueron realizados dos estudios coproparasitológicos de flotación (técnica de Bembrock). Ambos resultaron negativos. El hemograma y la bioquímica sanguínea no mostraron alteraciones. Las heces se recolecta- 
ron durante tres días consecutivos, conservándose con frío. Mientras se realizaban los estudios se indicó una dieta gastrointestinal comercial.

Luego del primer examen coproparasitológico negativo, se indicó un tratamiento empírico con antibiótico metronidazol en suspensión ( $25 \mathrm{mg} / \mathrm{kg}$ cada 12 h), el cual mejoró el cuadro digestivo, pero con el correr de los días manifestó una recidiva.

Se decidió realizar nuevos estudios de materia fecal, examinando las muestras antes de las 2 horas de la recolección. Se efectuaron extendidos con tinción Ziehl-Neelsen modificada y se practicaron técnicas coproparasitológicas de flotación (Sheater) y coprocultivos. Los resultados de tales exámenes revelaron la presencia de Tritrichomonas foetus, Giardia duodenalis, Criptosporidium sp y Demodex gatoi. A su vez, el cultivo evidenció la existencia de Enterococcus sp.

Luego del hallazgo de D. gatoi en los estudios coproparasitológicos, se realizaron estudios de piel y pelos (tricografia), tomas de muestras con cinta de acetato y raspados cutáneos, los cuales resultaron positivos a la presencia de huevos y ácaros adultos de D. gatoi. También se efectuaron estudios de retrovirales como leucemia felina e inmunodeficiencia felina (SpeedFiV/ $\mathrm{FeLv}$, Laboratorio Virbac), pero el resultado fue negativo para ambas patologías.

A partir de los resultados obtenidos, el paciente fue tratado en forma específica para $D$. gatoi con pipetas Advocate de Laboratorio Bayer (Imidacloprid $100 \mathrm{mg}$ y Moxidectina $10 \mathrm{mg}$ ), repitiendo el tratamiento a los 15 días. Al culminar la medicación se realizaron estudios de materia fecal y tricografía, obteniéndose resultados negativos para demodicosis.

\section{RESULTADOS}

Se descubrieron ejemplares adultos del ácaro $D$. gatoi en las muestras fecales de un felino doméstico. Los parásitos revelaron una longitud de 90 a $100 \mathrm{mi}$ crómetros, cuerpo redondeado y un opistosoma más pequeño que el de $D$. cati (Figura 2).

También se observaron huevos, que se caracterizaron por ser ovoides y medir 40 micrómetros cúbicos en las tricografías (Figura 3).

El tratamiento instaurado fue exitoso.

\section{DISCUSIÓN}

La demodicosis es una enfermedad parasitaria poco frecuente en la clínica felina, siendo éste el primer reporte de D. gatoi en Argentina. Al poco tiempo otro gato reveló la misma afección. A diferencia de lo que ocurre con $D$. cati, en los gatos no se encuentra asociado a estados de inmunosupresión ${ }^{1}$. En el caso descrito, el paciente presentó los signos dermatológicos descriptos en la literatura: exceso de lamido de la piel, prurito y leve eritema ${ }^{1,5}$.

El diagnóstico se realizó mediante una técnica coproparasitológica de flotación, debido a que los ácaros

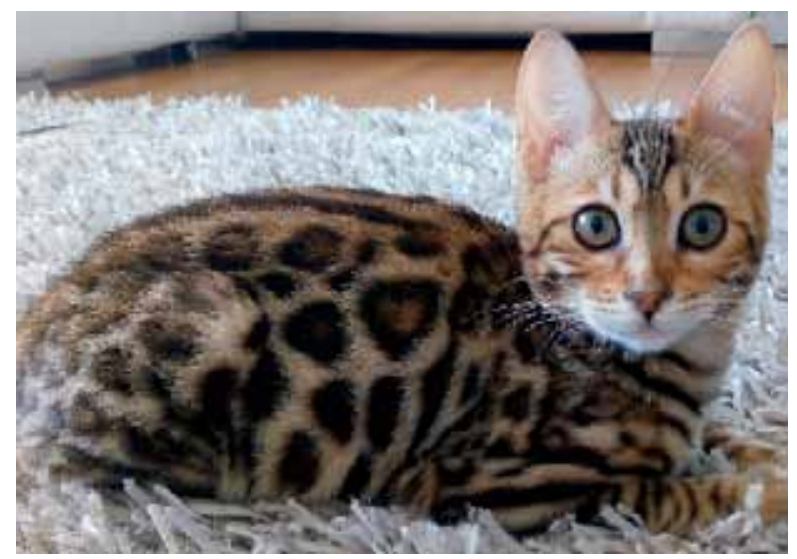

Figura 1. Hembra de raza Bengali, 4 meses de edad, castrada, con prurito de intenso a moderado y lamido excesivo.

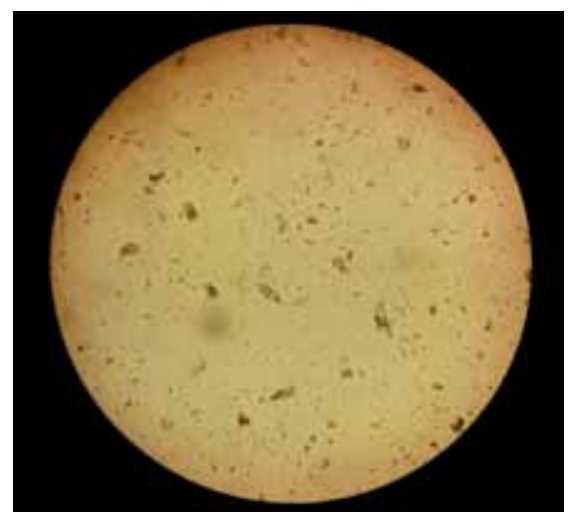

Figura 2. La técnica de flotación de Sweater permitió la observación de Demodex gatoi adultos.

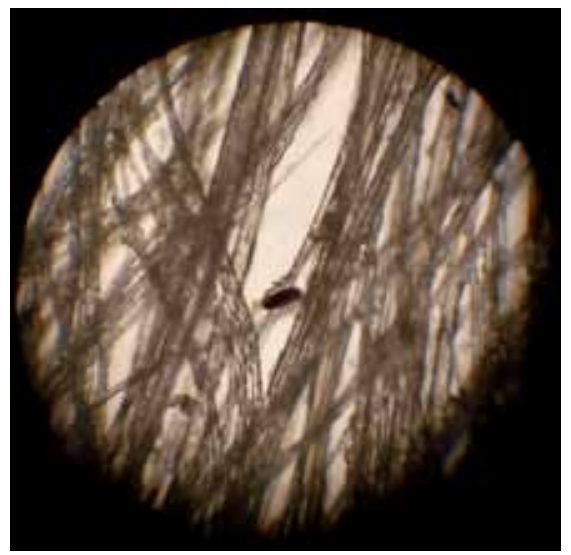

Figura 3. Identificación de huevos de Demodex gatoi en pelos obtenidos del paciente (tricografia).

son ingeridos accidentalmente por el lamido excesivo que realiza el gato debido al prurito ${ }^{1,7}$.

En cuanto al tratamiento, ambos gatos respondieron a la aplicación de Advocate (moxidectina + imidacloprid) en formulación tópica, con un intervalo de 15 días. El mismo tratamiento había sido ya reportado como efectivo en algunas ocasiones ${ }^{8}$ constituyéndose como una herramienta más efectiva que los baños de sulfuro limoso $2 \%^{1,5}$.

Después de haber negativizado la parasitosis, ambos gatos presentaron un síndrome de hipersensibili- 
dad post-tratamiento. Se realizaron tres raspajes de piel, tricografías y citologías con cinta de acetato en intervalos de 30 días, cuyo resultado fue negativo.

La hipersensibilidad post-tratamiento se manifestó con intenso prurito a pesar de la ausencia de ácaros en la piel. Esta anomalía ya había sido descrita como un síndrome similiar al que ocurre con la sarna sarcóptica en perros, en los cuales existe una hipersensibilidad de tipo I a antígenos del acaro ${ }^{1}$.

Los gatos fueron tratados con prednisolona a dosis $1 \mathrm{mg} / \mathrm{kg}$ cada $24 \mathrm{~h}$, observándose mejoría clínica a las $48 \mathrm{~h}$. Se continuó con la terapia de esteroides durante 10 días luego de remitidos los signos clínicos, seguida posteriormente con dosis decrecientes y de días alternos, hasta suspender el tratamiento.

Aunque es una enfermedad rara en los gatos domésticos, este hallazgo adquiere relevancia ya que es el primer registro en nuestro país. Se deberá tener en cuenta, entre los diagnósticos diferenciales del prurito en felinos, sobre todo si proceden de comunidades felinas (como criaderos o refugios) o bien si realizan actividades fuera del hogar.

Finalmente, es importante recalcar que al ser una parasitosis contagiosa entre ejemplares adultos, todos los animales de una casa, refugio o criadero deberán ser tratados.

\section{REFERENCIAS}

1. Beale K. 2012. Feline demodicosis: a consideration in the itchy or overgrooming cat. J Feline Med Surg 14: 209-213.

2. Beugnet F. 2018. Textbook of clinical parasitology in dogs and cats, 1st. edition, Ed. Servet (Vetbooks.ir), p. 275-277.

3. Desch CE, Stewart TB. 1999. Demodex gatoi: new species of hair follicle mite (Acari: Demodecidae) from the domestic cat (Carnivora: Felidae). J Med Entomol 36: 167170.

4. Kano $\mathbf{R}$ et al. 2012. Feline demodicosis caused by an unnamed species. Res in Vet Sci 92: 257-258.

5. Little S. 2014. El gato: medicina clínica y tratamiento, $1 \mathrm{ra}$. ed., edit. Intermédica, p 567-568.

6. Neel JA, Tarigo J, Tater KC, Grindem CB. 2007. Deep and superficial skin scrapings from a feline immunodeficiency virus-positive cat. Vet Clin Pathol 36: 101-104.

7. Saari SA et al. 2009. Demodex gatoi associated contagious pruritic dermatosis in cats. A report from six households in Finland. Acta Vet Scand 20: 51-40.

8. Short J, Gram D. 2016. Successful treatment of Demodex gatoi with 10\% imidacloprid / 1\% moxidectin. J Am Anim Hosp Assoc 52: 68-72.

9. Silbermayr K et al. 2013. The first case of Demodex gatoi in Austria, detected with fecal flotation. Parasitol Res 112: 2805-2810. 